\title{
Capelin and herring as key species for the yield of north-east Arctic cod. Results from multispecies model runs*
}

\author{
JOHANNES HAMRE \\ Institute of Marine Research, P.O. Box 1870 Nordnes, N 5817 Bergen, Norway. E-mail: johannes.hamre@imr.no
}

\begin{abstract}
SUMMARY: A conceptual temperature dependent multispecies model for stock interactions and harvesting of herring, capelin and cod in the Norwegian Sea-Barents Sea region has been developed. The concept presupposes that good recruitment of herring and cod is linked to warm ocean climate, which may occur with a frequency of 8 to 10 years. Strong herring year classes overlap the distribution of capelin larvae in 3-4 years causing mass mortality of the capelin fry, and depletion of the capelin stock. At the same time the herring is about to leave the Barents Sea, and lack of food in subsequent years reduces the potential yield of cod. Immature cod is the main predator on mature capelin and cannibalism is an important factor in reducing the abundance of juvenile cod when the capelin stock is rebuilding. The model is used in a study of the effects of different fishery management strategies on stocks and yield. Results show that optimum yield of cod is obtained by high fishing mortality on immature cod from the end of a warm period until the spawning stock of capelin is rebuilt. This fishing strategy will result in large fluctuation in the yearly cod catches but yield an optimum average biomass production of capelin and an optimum potential catch of cod. These results are in accordance with the catch history of cod. Prior to the 1970 s, the effort of the fishery in the Barents Sea followed to a large extent the abundance of immature cod, resulting in large catches when the stock was abundant. The yearly catches varied from 0.4 to 1.3 million tonnes, but the average catch obtained in the two periods 1950-1958 and 1959-1969 are the highest on record. Moreover, the trawlers fished with small meshes in the cod end, discarding considerable quantities of the smallest fish. It is concluded that the interaction between climate and fish stocks, and fish stock interactions in the north east Atlantic region, are of fundamental importance to the dynamic of the processes which govern the fish production of the region.
\end{abstract}

Key words: multispecies model, ecosystem, management, yield.

\section{INTRODUCTION}

Capelin was the dominating plankton feeder in the Barents Sea in the 1970s and first half of the 1980s. The stock formed the basis for the largest fishery in Europe with a record catch in 1977 of nearly 3 mill. tonnes, and the total biomass production is estimated to be some 8 million tonnes (Hamre and Tjelmeland, 1982; Gjøsæter, 1997). In 1983-86 a strong herring year class occurred in the southern

\footnotetext{
*Received October 9, 2000. Accepted March 14, 2002
}

part of the Barents Sea, and coincided with a dramatic fall in the recruitment to the capelin stock, which collapsed in 1986. The lack of prey fishes in subsequent years caused mass mortality in the fisheating stocks of fish, sea birds and marine mammals. It is assumed that the collapse of the capelin was associated with the occurrence of the herring, which had been absent since the late 1960s (Hamre,1985; Anon., 1987, Moksnes and Øyestad, 1987; Gjøsæter and Bogstad, 1998).

The stock evolution in the Barents Sea in the 1980s was the background for the development of a 
conceptual model for the fisheries in the Norwegian and Barents Seas (Hamre, 1988; Hamre and Hatlebakk, 1998). The model "Systmod" was developed in cooperation between The Institute of Marine Research (IMR) and Norsk Regnesentral (Norwegian Computing Center). So far it includes herring, capelin and cod.

The conceptual hypothesis of the model presupposes that the herring has a decisive impact on the recruitment of capelin and that this stock interaction is governed by periodic changes in the ocean climate. A warm climate provides good recruitment of herring and cod, but the presence of strong year classes of herring in the Barents Sea entail mass death of capelin fry. These ecological interrelations are the most powerful dynamic factors in the system, and determine the biomass production of catchable fish in the Barents Sea. The main evidence, which supports the hypothesis of the model, is summarised below.

\section{THE CONCEPT}

The physical conditions in the Norwegian Sea Barents Sea region are governed by the inflow of Atlantic water through the Faroe-Shetland Channel (Fig. 1).

Two main branches of the Atlantic Current create two separate ecosystems, one in the North Sea and one in the Norwegian Sea-Barents Sea. In the latter area, the interface between the inflow of warm Atlantic water and the cold Arctic water, provides upwelling and the physical basis for two highly productive areas, one in the Norwegian Sea along the Polar front, and one in the marginal ice zone of the Barents Sea.

Relevant features of the general biology of the main fish stocks are illustrated in Figure 2. Most of the rich plankton production in the upwelling areas has been harvested by the adult Norwegian springspawning herring Clupea harengus in the Norwe-

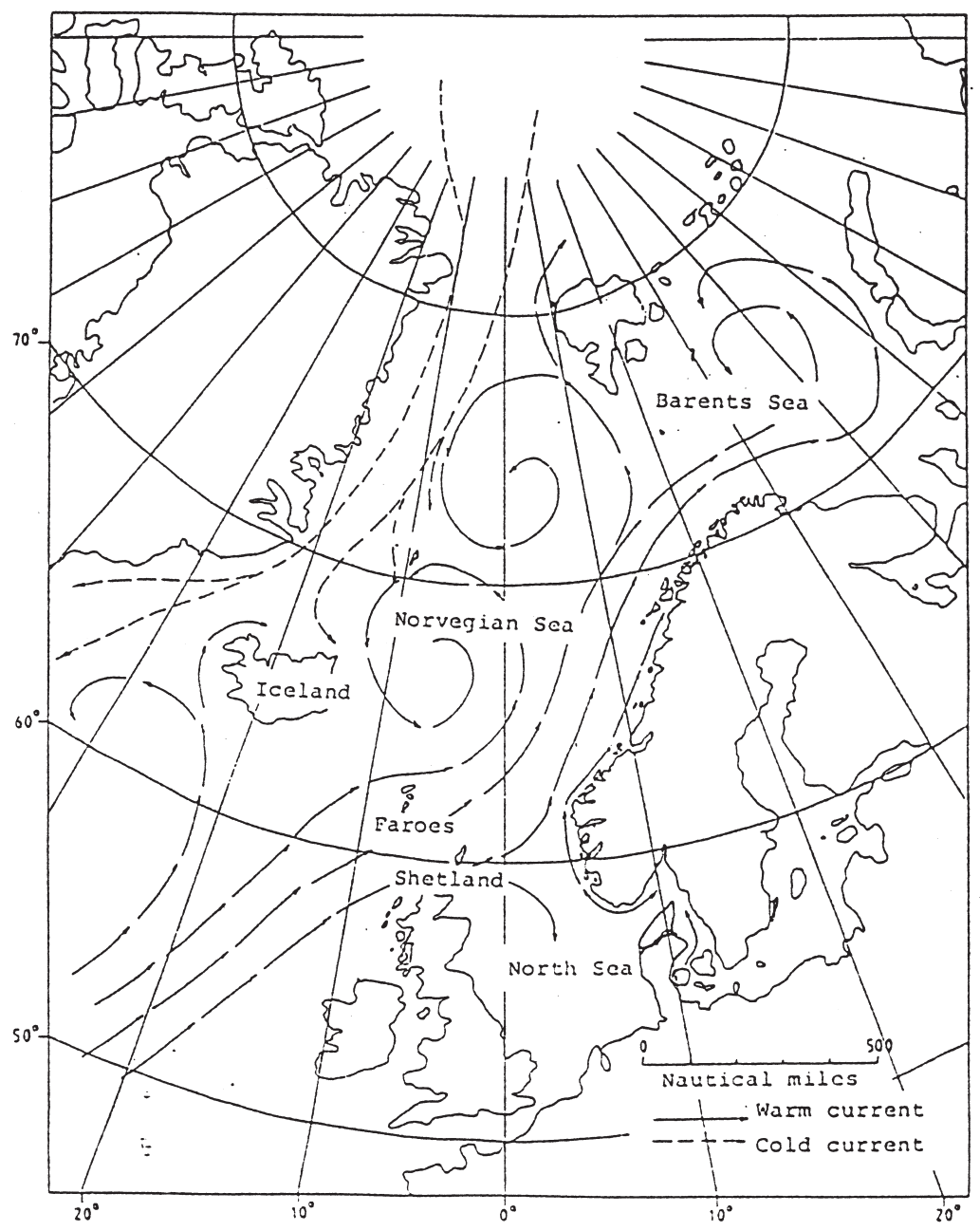

FIG. 1. - The current system of the Nordic and Barents Seas 


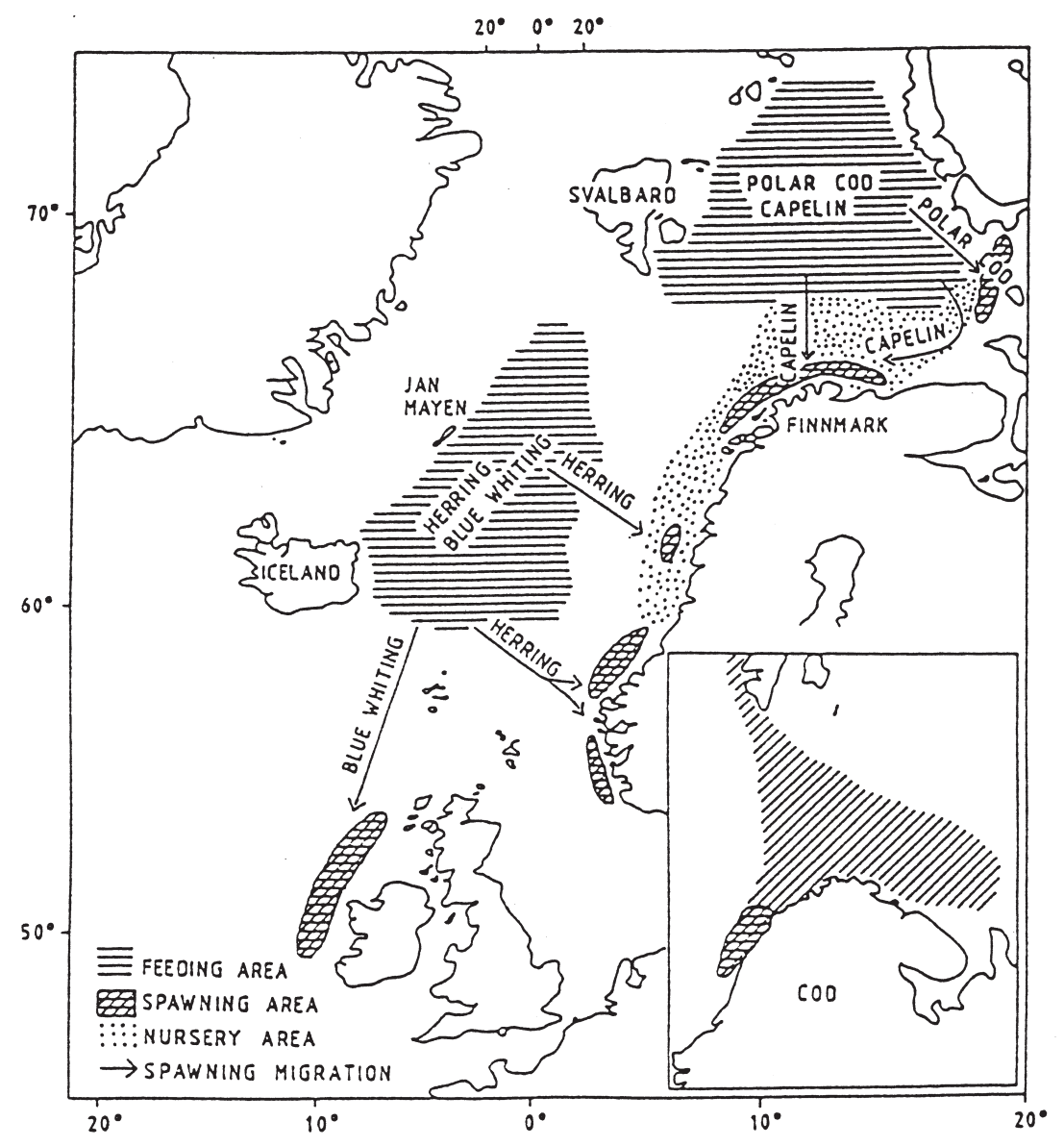

FIG. 2. - Distribution areas of main stocks in the Norwegian Sea and the Barents Sea.

gian Sea, and the capelin (Mallotus villosus) in the Barents Sea. The capelin is the main plankton feeder in the Barents Sea, but in years with strong herring year classes the juvenile herring plays an important part as prey species in the area. The capelin has a short life span and most of the fish spawn only once. Herring and capelin are the main food sources for a large variety of stocks, but the northeast Arctic cod (Gadus morhua) is the largest predator and plays a decisive role in the balance of predators and prey (Bogstad and Mehl, 1997). The stocks spawn on the Norwegian coast, and the spawning migrations of the plankton feeders transfer huge quantities of fish biomass from distant waters to the Norwegian continental shelf and to the southern parts of the Barents Sea.

The adult herring stock wintered in Icelandic waters prior to the $60 \mathrm{~s}$. This has changed in later years. The adult herring as well as the juveniles are now feeding in the eastern Norwegian Sea, and are wintering in Norwegian fjords.

Two large semipelagic stocks occur in the region, blue whiting and polar cod. The semipelagic stocks are however of marginal importance as prey species in this system because they spawn in other areas.

During summer the capelin feed in the marginal ice zone but accumulates in front of the south moving ice boarder during autumn. In winter the maturing stock migrates towards the coast for spawning, and it is during this spawning migration the capelin spawners become available to the immature cod (the mature cod is elsewhere for spawning). In the southern part of the Barents Sea the distribution of juvenile herring overlaps the distribution of the capelin larvae, which affects the survival of capelin frey. These stock interactions are the most powerful conceptual factors of the model (Hamre, 1994; Gjøsæter, 2000).

The sea temperature series from the Kola meridian transect $\left(33^{\circ} 30^{\prime} \mathrm{E}, 70^{\circ} 30^{\prime} \mathrm{N}\right.$ to $\left.72^{\circ} 30^{\prime} \mathrm{N}\right)$, is considered a good indicator of thermal conditions for the entire Barents Sea region. The series goes back to the turn of the previous century and mean values have been calculated by averaging, along the transect and vertically from 0 to $200 \mathrm{~m}$ water depth (Bochkov, 1982; Tereshchenko, 1996). The annual 


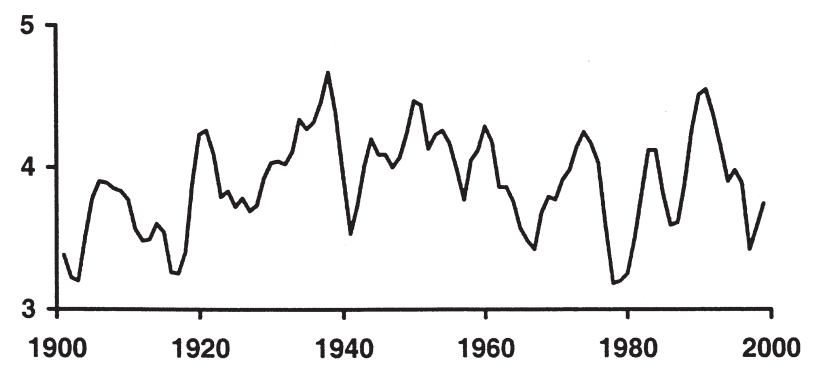

FIG. 3. - Mean annual temperature $\left({ }^{\circ} \mathrm{C}\right)$ in the Barents Sea (Kola section, smoothed over 3 years).

mean temperature in the period 1900-2000 is shown in Figure 3. The temperature varies periodically with 8 to 15 years between warm periods, and the periods of warm climate coincide with strong year classes of herring and cod (Marty and Federov, 1963; Sætersdal and Loeng, 1984).

In conclusion, the evidence indicates that the herring and capelin are the key prey species at fish level of the food chain in the Norwegian Sea-Barents Sea ecosystem, and the cod is the dominant predator. The abundance of immature herring determines the survival of 0-group capelin, whereas the abundance of immature cod determines the mortality of maturing capelin. The dynamics of the system are governed by the inflow of Atlantic water, which determines distribution, recruitment success and growth of the main species involved. Based on this knowledge, the structure of climate and stock interrelationships is modelled, and a technical version of the model was published by Hamre and Hatlebakk (1998). Input data are stock abundance data in number by age and length groups, weight by length groups, estimated consumption of cod by species, annual mean temperature in the Kola transect and model parameter data files of temperature, length at maturation, recruitment, growth and mortality. The model parameters are estimated by comparing model results to data. A brief description of the model structure is outlined below.

\section{MODEL STRUCTURE}

The model is length-based, and the growth in length per month is modelled with the following equation (von Bertalanffy, 1938):

$\Delta L(t)=l(t+T)-L(t)=\left(L_{\infty}-L(t)\right) \cdot\left(1-e^{-K T}\right) \cdot M(t)$

where $t$ is a time variable and $T$ an interval of fixed length. $L$ is the maximum length of the fish. $M(t)$ is a factor, which distributes the yearly growth on the different months. $K$ is the growth parameter, which determines the growth related to the size of the stock and environmental factors (capelin and herring). $K$ is determined by the following equations:

$$
K=\left(a+b \cdot e^{-d \cdot B(t)}\right) \cdot g
$$

$B(t)$ is the stock abundance at time $t$. The exponential term regulates the density dependent growth. $g=a+b \cdot T(T=$ temperature anomaly $)$ is a function to regulate the growth according to variation in the climate. For cod the parameter $K$ is computed according to the equation:

$$
K=a\left(2.2-0.4 \frac{C C O D C}{C O D}\right)+b \cdot \frac{C C O D}{C O D}
$$

CCOD is the consumption of herring, capelin and cod by cod, CCODC the consumption of capelin by cod, and COD the stock biomass. The parameter a determines the contribution to the growth from other prey species. The consumption of other prey species is related to the consumption of capelin and is estimated from data in Bogstad and Mehl (1997).

The juveniles are recruited to the stock in January at age 1 . To describe the relation between the spawning stock in the springtime and the number of recruits in January the following year, the BevertonHolt function is used:

$$
R=\frac{M \cdot B}{H+B} e^{a \cdot T}
$$

where $R=$ recruitment; $M=$ maximum recruitment; $B=$ spawning stock biomass; $H=$ the half- value; $T$ $=$ temperature anomaly; $\mathrm{a}$ is a parameter. Two levels of $M$ are used for simulating cod and herring recruitment, one low (cold period) and one high, when $T$ exceeds a given value.

The effects of juvenile herring on the survival of capelin fry $\left(\mathrm{R}_{0}\right)$ is modelled by a reduction factor proportional to the strength of the age groups 1 to 3 :

$\mathrm{R}_{1}=\mathrm{R}_{\mathrm{o}} \cdot\left(1-\left(\mathrm{a}_{1} \cdot \mathrm{HER}_{1}+\mathrm{a}_{2} \mathrm{HER}_{2}+\mathrm{a}_{3} \cdot \mathrm{HER}_{3}\right)\right)$

$\mathrm{HER}_{1}$ denotes 1-group herring, $\mathrm{HER}_{2}$ 2-year-old herring, $\mathrm{HER}_{3} 3$ year-old herring.

All the species mature at the turn of the year. The maturity ogive in each length group is computed from a logistic function (Tjelmeland, 1987):

$$
M(l)=\frac{1}{1+e^{4 P_{1}\left(P_{2}-l\right)}}
$$


where $l$ denotes mean length in the length group (midpoint in length interval), $P_{1}$ and $P_{2}$ are parameters.

In computing survival per length group (i) per month $(\mathrm{t})$ the following equation is used:

$\mathrm{N}_{\mathrm{i}, \mathrm{t}+1}=\mathrm{N}_{\mathrm{i}, \mathrm{t}} \cdot(1-\mathrm{G}) \cdot(1-\mathrm{M}) \cdot\left(1-\mathrm{P}_{\mathrm{i}}\right) \cdot\left(1-\mathrm{F}_{\mathrm{i}}\right)$

where

$N_{i}$ is number of survivors in length group i

$\mathrm{G}$ is spawning mortality (capelin only)

$\mathrm{F}$ is fishing mortality

$\mathrm{P}$ is predation mortality

$\mathrm{M}$ is natural mortality (not including predation)

Another parameter in the model determines the fraction of mature capelin, which survives after spawning (1 April).

The monthly mortality rate caused by predation is computed by species. For capelin this is:

$$
\mathrm{P}_{\mathrm{i}}=\mathrm{K}_{\mathrm{C}} \cdot\left(\mathrm{a}_{0} \cdot \mathrm{COD}_{\mathrm{im}}+\mathrm{a}_{1} \cdot \mathrm{COD}_{\mathrm{m}}\right)
$$

For Barents Sea herring:

$$
\mathrm{P}_{\mathrm{i}}=\mathrm{K}_{\mathrm{H}} \cdot \mathrm{COD} /(1+\mathrm{b} \cdot \mathrm{CAP})
$$

For cod:

$\mathrm{P}_{\mathrm{i}}=\mathrm{K}_{\mathrm{CO}} \cdot \mathrm{COD} /\left(1+\mathrm{b}_{1} \cdot \mathrm{CAP}+\mathrm{b}_{2} \cdot \mathrm{HER}_{\mathrm{im}}\right)$

where

$\mathrm{P}_{\mathrm{i}}$ is predation mortality rate for length group $\mathrm{i}$

$\mathrm{K}_{\mathrm{C}}, \mathrm{K}_{\mathrm{H}}$ and $\mathrm{K}_{\mathrm{CO}}$ are constants fore capelin, herring and cod

CAP, HER and COD are total stocks in weight of capelin, herring and cod, and the

indices $\mathrm{m} / \mathrm{im}$ indicate mature/immature stocks respectively

$\mathrm{a}$ and $\mathrm{b}$ are parameters estimated from consumption data by species

Parameter estimation has been done by a step-bystep procedure based on biological knowledge of the system and experiences gained in the model runs. The impact of changes in the climate is modelled by a sine curve fitted to observed temperature anomalies in the Kola section (Fig. 4). The recruitment parameters of capelin are determined by comparing modelled numbers of 2 years old to acoustic estimates of the age group in autumn, and the parameters of herring and cod by comparing modelled numbers of 3 years old to the corresponding VPA-estimates of the stocks. The stock in numbers is con-

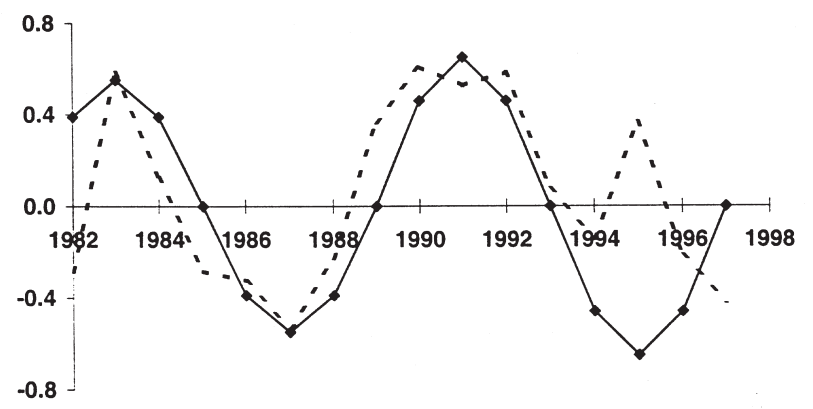

FIG. 4. - Simulated and observed (Kola section, dotted line) temperature anomalies $\left({ }^{\circ} \mathrm{C}\right)$ with 8 years between warm ocean climate periods.

verted to stock biomass by observed weight by length-groups.

The predation parameters of cod are derived from the estimates of the yearly consumption of cod by prey species. Such data are available from 1984 onwards (Bogstad and Mehl, 1997). The predation parameters of cod are of basic importance and the period after 1982 is selected for fitting the model results to data. The results of fits of stock abundance in number and weight are shown in Figure 5. The fits are reasonably good whether the sine curve or the observed temperature anomalies are used as basis for the simulation, even in the years 1994-1995 when the difference between modeled and observed temperature anomalies are significant. This is related to how the recruitment parameters are determined and the nature of cod cannibalism.

The impact of the climate on capelin recruitment seems to be negligible but the effects of herring recruits on the capelin are the most powerful dynamic element in the model. This takes place in warm periods when the fits of the sine curve to observed $\mathrm{T}$ are reasonably good. The strong herring year classes are triggered by high-temperature anomaly $(\mathrm{T})$, and the model selects a high maximum recruitment level ( $\mathrm{M}$ in the recruitment formula), when $\mathrm{T}$ exceeds a predefined value (0.4). For herring the high $\mathrm{M}$ level is determined to be 20 times higher than the low $\mathrm{M}$ value, and the exponential factor (a) in the recruitment formula is found to be negligible. Since the observed $\mathrm{T}$ in 1995 is below 0.4, which triggers the high-level $\mathrm{M}$, the model estimates of recruitment for herring will be the same whether based on the sine curve or the observed values.

The recruitment relationship of cod to temperature is different. The recruitment figures of 1-group cod is closely related to the temperature and less dependent on the peak T-value which triggers a strong herring year class. This is modelled by a rel- 
Capelin biomass

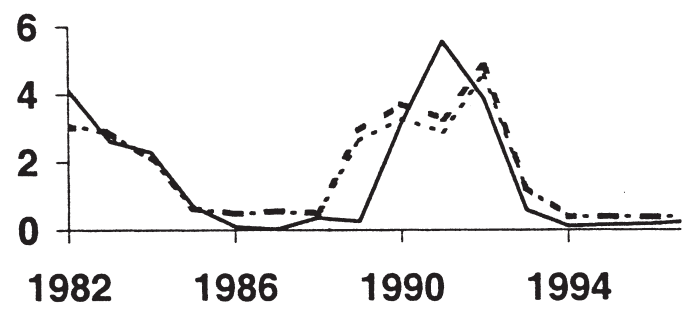

Cod biomass
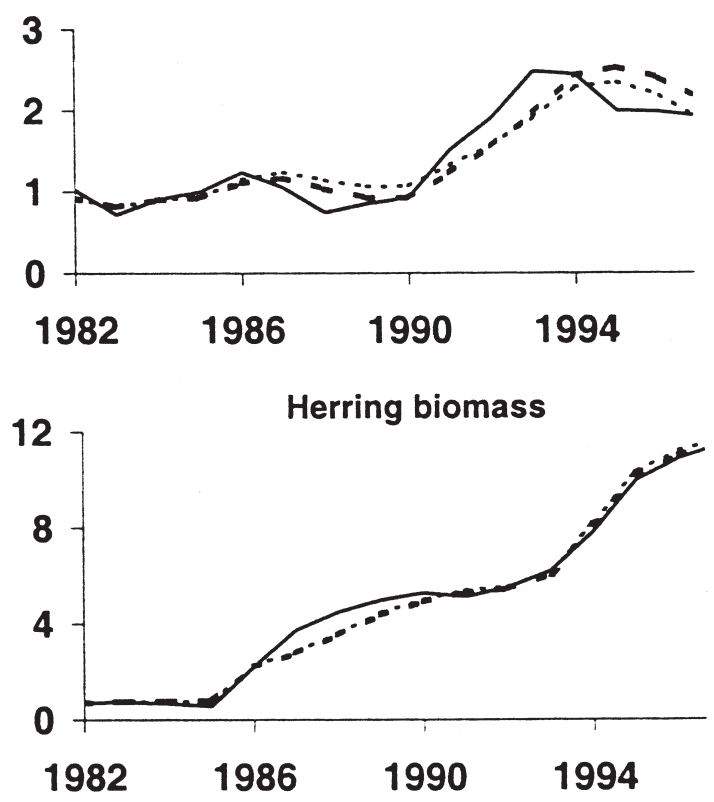

Capelin number
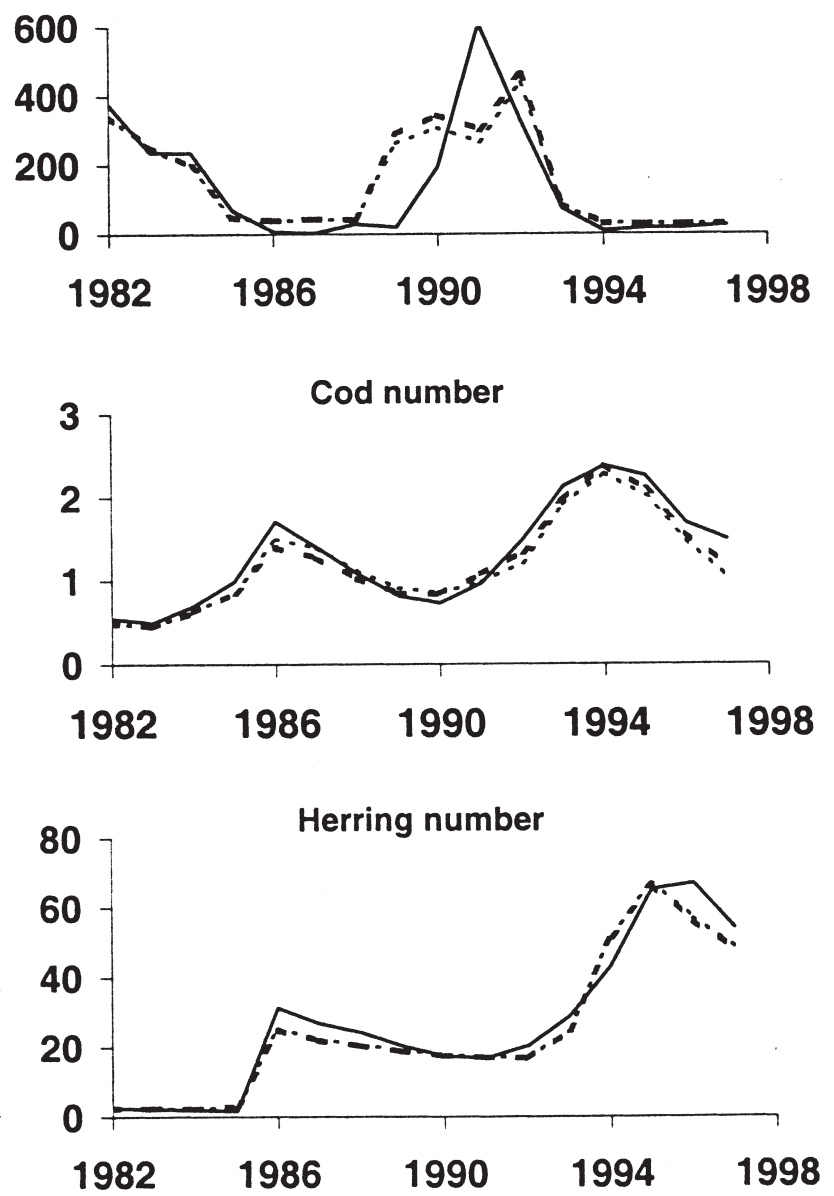

FIG. 5. - Observed and simulated (dotted lines) stocks in weight (million tonnes) and number (billion), using observed temperature (brand dots) and the sine curve in the simulation.

ative high parameter value of the exponent (a) in the recruitment formula for cod, and less differences in the levels of M. This will simulate good recruitment of cod in 1994-1995 as 1- group, but due to cannibalism in the subsequent years, these age groups are depleted as 3-year olds (Fig. 6). The cod cannibalism in 1995, 1996 and 1997 is estimated to 0.4, 0.6 and 0.4 million tonnes of young cod respectively (Bogstad and Mehl, 1997), and the cod predation parameters are tuned against these data. When the recruitment of cod as 3-group is modelled in this way, the modelled recruitment will be approximately the same whether the sine curve or the observed values of temperature are used in the simulation. Using the sine curve, the simulated 1-group year classes 1994-1996 of cod will however be considerably reduced, and the corresponding food supply of cod from own progeny will be lost in the simulation. This should be born in mind when using the model for prognostic purposes.

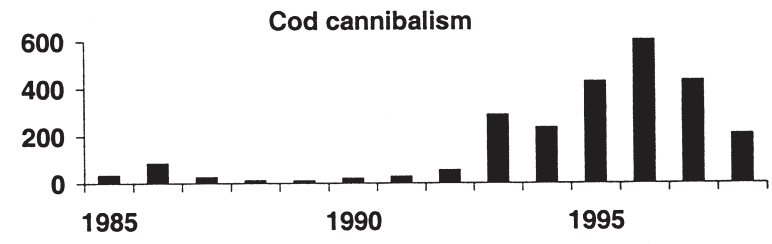

FIG. 6. - Cod cannibalism (thousand tonnes) in 1985-1998.

Assuming a cyclic change in the ocean climate, the model is used in analysing the impact of different fishery management strategies on stock and yield.

\section{MANAGEMENT STRATEGY ANALYSIS}

The catch is modelled by fishing mortality (F) and by catch quotas by season and year, the fishery being closed if and when the quota is taken. The 
capelin winter fishery is closed when the maturing stock is reduced to a predetermined lowest acceptable level.

The stock estimates as of 1 January 1982 are chosen as initial stocks of the basic runs, and the runs cover periods of 40 years. Prior to 1999 the model uses historical data on catch and temperature. Warm periods with a cycle of 8-9 years are observed in recent years and a sine curve with corresponding amplitude and frequency is chosen as prognosis for the further development of the climate. The strategy chosen for the period after 1999 is similar to the exploitation pattern of the stocks in the 1990s, and is for capelin: no autumn catch and a winter catch limit of 800,000 tonnes, allowing at least 500,000 tonnes to spawn; for cod: a $\mathrm{F}$ of 0.7 and a catch limit of 900,000 tonnes; for herring: a $\mathrm{F}$ of 0.2 and a catch limit of 1.2 million tonnes. Output files of catch and stock biomass are processed on spreadsheet and illustrated in Figures 7 and 8.

The capelin catches fluctuate between 0 and well over 0.8 million tonnes, with an average catch of close to 0.4 million tonnes (Fig. 7). In about half of each climate period (3-4 years) the maturing capelin
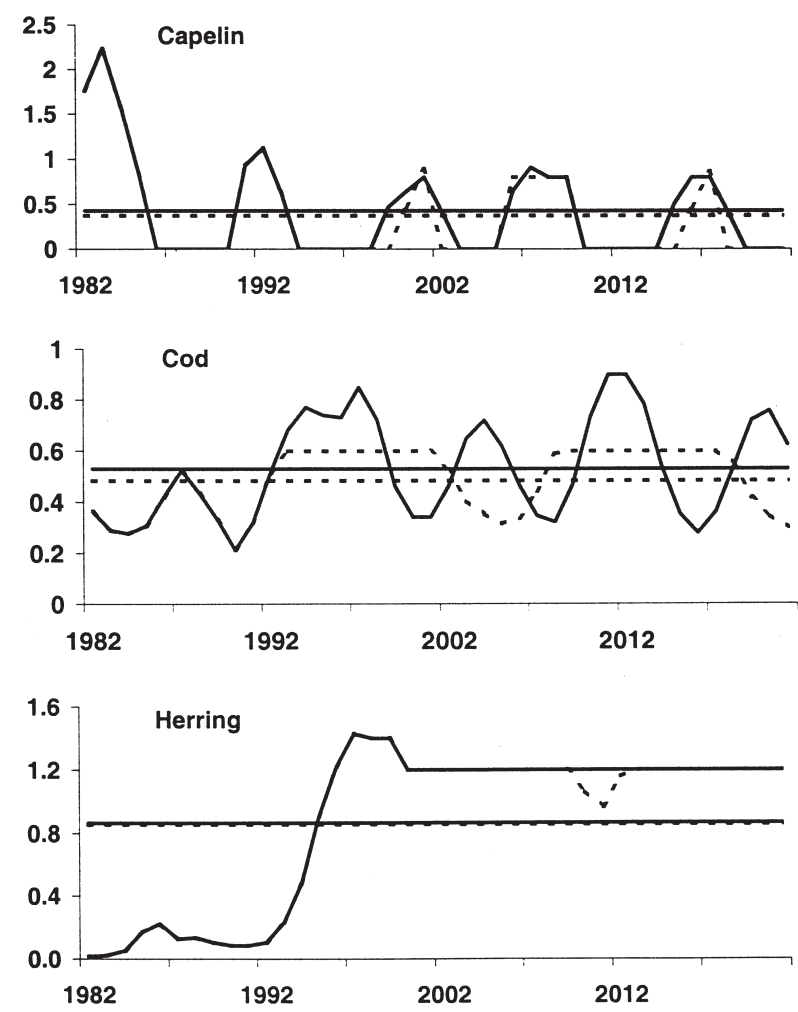

FIG. 7. - Simulated catches (million tonnes) in 1982-2022 using observed data prior to 1999 . The line parallel to the $\mathrm{x}$-axis shows the average catch. The dotted lines show the corresponding catches when the catch limit of cod is reduced to 0.6 million tonnes from 1993 onwards. For further explanation, see text
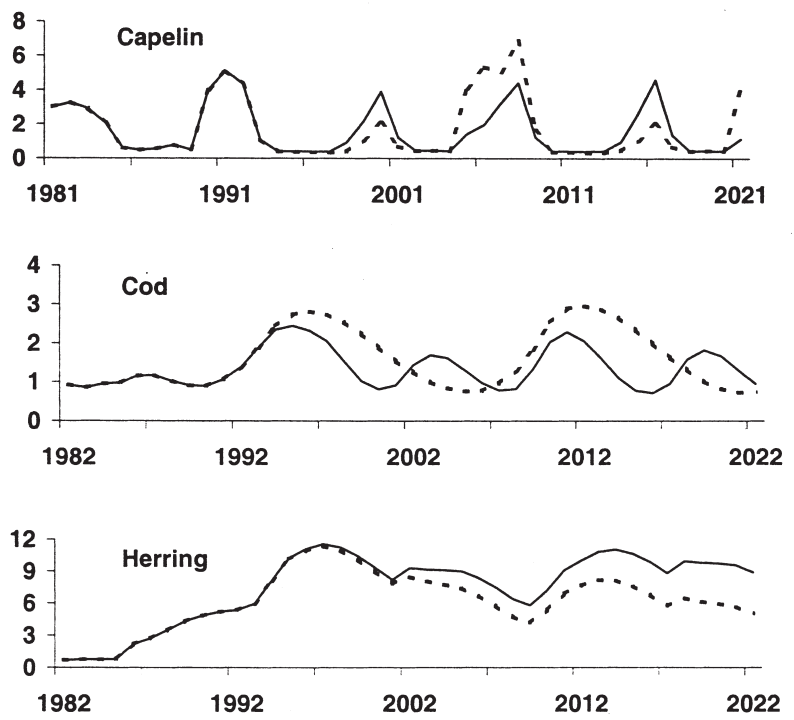

FIG. 8. - Simulated stocks (million tonnes) corresponding to the management strategies in Figure 7.

stock is below the lowest acceptable level for fishing, i.e. 0.5 million tonnes. The fluctuation in the catches by periods is related to the pattern of the sine curve and stocks interaction of the system.

The cod catches fluctuate between 0.3 and 0.9 million tonnes with an average of some 0.55 million tonnes. The corresponding development in stock abundance (Fig. 8) reflects the effects of the basic hypothesis that a warm climate is favourable for recruitment of herring and cod, but bring about collapses in the capelin stock. The reduced availability of capelin has consequences for the next generations of cod, for which the growth in biomass is correspondingly reduced. This will in turn result in an increase in the recruitment and growth of the capelin stock during the next years and so on. This alternation in stock size between the cod (the predator) and capelin (its prey) illustrates the well-known phenomenon of the Lotka-Volterra predator-prey relationship (Volterra, 1928).

In the basic run herring yielded an average catch of about 1.2 million tonnes from the early 1990s onwards, without increasing the fishing mortality above 0.2 , although the recruitment of herring fluctuates with 1 or 2 abundant year classes every 8 years. The simulations indicate that this is the optimum yield of herring and may be obtained by stable yearly catches, provided that the time lags between warm periods are short (8 years). An important factor to this is that the individual growth of herring increases in warm periods when the adult stock is reduced in number, and this increases the biomass 
production and compensates for the reduction of the stock in numbers.

The most important question of fishery management policy in the Barents Sea is concerned with the management of the cod stock. The fisheries industry wants stability, and in order to test the effect of constant cod catches on stocks and yield, the model has been run with a yearly catch limit of 600,000 tonnes of cod from 1993 onwards, keeping the other parameters unchanged. The results show (dotted lines in Figs. 7 and 8) that this strategy may create a new cycle in the predator-prey relationships between cod and capelin with a frequency of 16 years. Stability in the yearly catches of cod may thus not be achieved by reducing fishing mortality when the stock is abundant. In addition an accumulated cod stock may reduce the average obtainable catch of all the stocks significantly, including the cod itself. This is because a large immature stock of cod may prevent rebuilding of the capelin stock, which in turn may reduce the food supply for cod for a whole period ( 8 years), and a new cycle of 16-years may occur.

The effects of the capelin fishery and prolonged time lags between warm periods on the yield of cod, have also been tested by model runs. The results show that the gain in the catch of cod by a total ban on the capelin fishery is about 10 percent of the corresponding loss in the capelin catch, provided that the capelin is caught during winter and that at least 500,000 tonnes of capelin are allowed to spawn. Prolonged time lags between warm periods reduces the yield of herring considerably, but favors capelin recruitment and biomass production of capelin and cod.

\section{DISCUSSION}

In a context of multispecies interactions with a large number of mutually dependent parameters, no unique solution exists in fitting model results to data. The parameter estimates used in this study are moreover preliminary, because some are only roughly estimated and not systematically tuned to data. The validity and reliability of the model may thus be improved with respect to the magnitude of the estimates. However, the trends of development in stock and yield reflected by this model are probably more dependant on the validity of the concept on which the model is built than the accuracy of the parameter estimates. In the author's opinion, the good fits of model results to data indicate that the concept is valid, and that the system is predictable if one can predict the frequency of warm climate periods and strong year classes of herring and cod. If so, the model should be a valuable tool to quantify the main dynamic processes of the system. With this reservation in mind, some details of the model results will be commented on and discussed.

An ecological interpretation of the cod cannibalism is that the cod has adapted to the cyclic recruitment pattern of capelin by eating its own progeny when the capelin stock is depleted and is in a state of rebuilding. It seems obvious that if the nearly one and a half million tonnes of young cod eaten by older brothers and sisters in 1995-1997 had survived (Fig. 6), this could have prevented rebuilding of the capelin stock in the subsequent years and thus threatened the food supply for the coming generations of cod. This form of cannibalism for regulating stock abundance when the availability of prey species varies is a well known phenomenon among bird, and the ornithologists have termed it the KainAbel phenomenon (Newton, 1979).

The role of cod cannibalism in the system supports the findings that a constant yearly catch-quota regulation of cod may fail in managing the cod capelin fisheries on an optimal sustainable basis. It may also explain why the record catch of cod was obtained in the 1950s and 1960s, when the immature cod was heavily fished when the stock was abundant (3 to 6 years after recruitment of strong cod year classes). The trawlers fished at that time with small meshes in the cod end, and large quantities of the smallest cod were discarded. In this way the trawlers increased the Kain-Abel effect in the system. The yearly catches fluctuated between 0.4 and 1.3 million tonnes, but the average catch obtained is the largest on record.

In conclusion, the present study indicates that the biomass production of capelin is the driving force behind the obtainable yield of cod, the former being governed by the recruitment and life pattern of the herring. The superior steering factor of the system is linked to the ocean climate, which may alternate with warm and cold periods. Most of the production takes place in the warm periods, and has to be harvested when the stocks are large in order to obtain an optimal sustainable catch. This refers especially to capelin and cod, which cannot be accumulated in their most productive phase for the benefit of increased catches when the biomass production is low. This is due to the short life span of capelin and to the stock interaction between mature capelin and 
immature cod. The sustainable yield of herring seems to be more dependent on climate changes than on the stock interrelationships and may be harvested with constant yearly catch quotas when the time lags between warm periods are short. A high frequency of warm periods is favourable for the herring, but has a negative effect on the obtainable yield of capelin and cod. These interrelationships between climate and fish stocks may, to a large extent, determine the magnitude and variability of the total fish production in the north east Atlantic region.

\section{REFERENCES}

Anonymous. - 1987. Report of the Atlanto-Scandian Herring and Capelin Working Group, Copenhagen 27-31 October 1986. ICES C.M. 1987/Assess: 8.

Bertalanffy, L. von. - 1938. A quantitative theory of organic growth. Human Biol., 10(2): 181-213.

Bochkov, Y.A. - 1982. Water temperature in the $0-200 \mathrm{~m}$ layer in the Kola-Meridian in the Barents Sea, 1900-1981. Sb. Nauchn. Trud. PINRO 46: 113-122.

Bogstad, B. and S. Mehl. - 1997. Interaction between Atlantic cod (Gadus morhua) and its prey species in the Barents Sea. In: Forage Fishes in Marine Ecosystems. Alaska Sea Grant Report 9701.University of Alaska Fairbanks, Fairbanks, AK.

Gjøsæter, H. - 2000. Studies on the Barents Sea capelin (Mallotus villosus Müller), with emphasis on growth. $\mathrm{Ph} \mathrm{D}$ thesis Institute of Fisheries and Marine Biology, University of Bergen.

Gjøsæter, H. - 1997. The Barents Sea Capelin Stock (Mallotus villosus): A Brief Review. Proceedings Forage Fishes in Marine Ecosystems. Alaska Sea Grant College Program. AK-SG-9701, 1997: 469-484.

Gjøsæter, H. and B. Bogstad. - 1998. Effects of the presence of her- ring (Clupea harengus) on the stock-recruitment relationship of Barents Sea capelin (Mallotus villosus). Fish. Res., 38: 57-71.

Hamre, J. - 1985. Assessment and management of Barents Sea capelin. In: H. Gjøsæter (ed.), Proc. Soviet-Norwegian Symp. Barent Sea capelin, 14-17 August 1984, pp 5-24. Bergen, Institute of Marine Research.

Hamre, J. - 1994. Biodiversity and exploitation of the main fish stocks in the Norwegian Sea-Barents Sea ecosystem. Biodiver. Conserv., 3: 273-292.

Hamre, J. and E. Hatlebakk. - 1998. System Model (Systmod) for the Norwegian Sea and the Barents Sea. In: T. Rødseth (ed.), Models for Multispecies Management, pp. 93-115. PhysicaVerlag, Heidelberg New York.

Hamre, J. - 1988. Some aspects of the interrelation between the herring in the Norwegian Sea and the stocks of capelin and cod in the Barents Sea. ICES C.M 1988/H:42: 1-15. (Mimeo).

Hamre, J. and S. Tjelmeland. - 1982. Sustainable yield estimates of the Barents Sea capelin stock. ICES C.M. 1982/H:45: 1-24. (Mimeo).

Marty, J.J. and S.S. Fedorov. - 1963. Features of the population dynamics of marine Herring as seen from the Atlanto-Scandian stock Rapp. P.-v. Reun. Cons. perm. int. Explor. Mer, 154: 91-97.

Moksnes, E. and V. Øyestad. - 1987. Interaction of Norwegian sprin-spawning herring larvae (Clupea harengus) and Barents Sea capelin larvae (Mallotus villosus) in a mesocosm study. $J$. Cons. int. Mer., 44: 32-42.

Newton, I. - 1979. Population Ecology of Raptors. In: T. \& A. D. Poyser, Berkhamsted.

Sætersdal, G. and H. Loeng. - 1984. Ecological adaption of reproduction in Arctic Cod. Proc. of the Soviet-Norwegian Symp. Reproduction and Recruitment of Arctic Cod, pp.13-35. Inst. of Mar. Research, Bergen.

Tereshchenko, V. V. - 1996. Seasonal and year-to-year variations of temperature and salinity along the Kola meridian transect. ICES CM: 24

Tjelmeland, S. - 1987. Mortality on Barents Sea Capelin calculated by the IMR Multispecies Model for the Barents Sea. ICES C.M. 1987/H:55: 1-21 (Mimeo).

Volterra, V. - 1928. Variations and fluctuations of the number of individuals in animal species living together. J. du Cons. III: 1-51. 
